\title{
Electrocardiographic effects of isoprenaline in normal subjects and patients with coronary atherosclerosis ${ }^{1}$
}

\author{
' Harold Wexler, Jafer Kuaity, and Ernst Simonson \\ From Mount Sinai Hospital, 2215 Park Avenue, Minneapolis, Minnesota 55404, and the \\ Laboratory of Physiological Hygiene, University of Minnesota, Minneapolis, Minnesota, U.S.A.
}

The intravenous infusion of isoprenaline in normal subjects causes no significant electrocardiographic abnormalities. This is in sharp contrast to the remarkably ischaemic ST-T changes seen after infusing isoprenaline in patients with coronary artery disease. Limited experience thus far has been attended by no untoward reactions. In view of the simplicity and great sensitivity, we conclude that the isoprenaline infusion test is thus far a satisfactory method for differentiating normal subjects from coronary disease patients. It must be emphasized, however, that this is a preliminary report and further study of isoprenaline in patients with coronary disease is mandatory before advocating the routine employment of its use as a diagnostic tool.

During the past is years isoprenaline has gained a progressively important role in clinical medicine. Initially it was used to relieve

- bronchospasm in obstructive lung disease and subsequently has gained a great deal of clinical use in the treatment of cardiogenic shock, incomplete and complete atrioventricular block (Bluestone and Harris, 1965; Bellet, I963). Since isoprenaline is a beta-adrenergic stimulating agent with chronotropic, inotropic, and vasodilating properties, it has been used extensively in haemodynamic and -biochemical research related to the cardiovascular system (Mendez and Kabela, 1966; Ahn and Vasko, 1969; Lafontant, Feinberg, and Katz, 1962). Moreover, isoprenaline has been used in the evaluation of cardiovascular effects in normal subjects, in patients with coronary artery disease, and in patients with congestive heart failure (Dodge, Lord, and Sandler, 1960; Eckstein and Hamilton, 1957; Dodge and Murdaugh, 1957). In spite of its wide use in clinical application and research (Krasnow et al., 1964; Cohen et al., 1966), no systematic study of its electrocardiographic effects, in normal subjects and in patients with coronary heart disease, has been reported. Therefore, the purpose of this study is to provide this information.

Received 22 December 1970.

1 This work was supported in part by a grant from the Minnesota Heart Association and by a grant from the National Heart Institute, Bethesda, Maryland, U.S.A.

\section{Subjects}

Two age-matched groups of 14 clinically healthy subjects (Io men, 4 women, age range from $40-75$ years, mean age 52) and 17 patients with coronary heart disease ( 12 men, 5 women, age range from 4I-77 years, mean age 59.I) were investigated. All patients had at least one well-documented myocardial infarction, but none had sustained a myocardial infarction for at least 6 months before this study, none had taken any cardiac drugs, and none had undergone a recent change in the clinical status of their angina. The electrocardiograms had returned to normal in 6 of the coronary group, while 7 had only QRS residual abnormalities. In the remaining 3 patients, flattened or negative $T$ waves were also present in the baseline electrocardiograms. None in the patient group had ST changes before infusion of isoprenaline. In addition, a normal group of 15 subjects (8 women, 7 men, age range from 21 to 35 years, mean age 27.4 ) and a group of ro patients ( 2 women, 8 men, age range from $40-65$ years, mean age 53.4) with suspected coronary artery disease, but with normal response to the 'Master two step' test, were investigated. However, these latter two groups were not included in the statistical analysis.

\section{Method}

In all subjects a baseline standard 12-lead electrocardiogram was taken. After an intravenous infusion of about 10 to $20 \mathrm{ml} 5$ per cent glucose in water, a second control electrocardiogram was taken, followed by intravenous infusion of $0.2 \mathrm{mg}$ isoprenaline in $200 \mathrm{ml} 5$ per cent glucose in water at a rate of $\mathrm{I}-2 \mu \mathrm{g} / \mathrm{min}$, and continued until a heart 
TABLE I Mean changes of ST segment and $T$ wave before and after isoprenaline in I 4 normal subjects and 17 patients with coronary heart disease

\begin{tabular}{|c|c|c|c|c|c|c|c|c|c|c|c|c|}
\hline \multicolumn{7}{|c|}{ Normal controls } & \multicolumn{6}{|l|}{ Patients } \\
\hline Lead & $\begin{array}{l}S T \\
\text { Mean }\end{array}$ & $S D^{\star}$ & $P_{t} \dagger$ & $\begin{array}{l}T \\
\text { Mean }\end{array}$ & $S D$ & $P_{\mathrm{t}}$ & $\begin{array}{l}S T \\
\text { Mean }\end{array}$ & $S D$ & $P_{\mathrm{t}}$ & $\begin{array}{l}T \\
\text { Mean }\end{array}$ & $S D$ & $P_{\mathrm{t}}$ \\
\hline $\begin{array}{l}\text { I } \\
\text { aVF } \\
\text { V2 } \\
\text { V6 }\end{array}$ & $\begin{array}{l}-0.14 \\
-0.43 \\
-0.14 \\
-0.25\end{array}$ & $\begin{array}{l}0.31 \\
0.51 \\
0.36 \\
0.43\end{array}$ & $\begin{array}{l}0.10 \\
0.006 \\
0.16 \\
0.046\end{array}$ & $\begin{array}{l}0.39 \\
0.36 \\
1.21 \\
0.21\end{array}$ & $\begin{array}{l}0.90 \\
0.82 \\
0.96 \\
1.01\end{array}$ & $\begin{array}{l}0.12 \\
0.12 \\
0.0004 \\
0.45\end{array}$ & $\begin{array}{l}-I .85 \\
-I .24 \\
-2.35 \\
-I .85\end{array}$ & $\begin{array}{l}0.55 \\
1.95 \\
1.65 \\
1.01\end{array}$ & $\begin{array}{l}0.0001 \\
0.021 \\
0.0001 \\
0.0001\end{array}$ & $\begin{array}{l}0.22 \\
0.15 \\
0.78 \\
0.78\end{array}$ & $\begin{array}{l}1 \cdot 97 \\
2 \cdot 55 \\
2 \cdot 90 \\
2 \cdot 25\end{array}$ & $\begin{array}{l}0.68 \\
0.83 \\
0.31 \\
0.19\end{array}$ \\
\hline
\end{tabular}

$\star \mathrm{SD}=$ standard deviation.

$\uparrow P_{t}=$ statistical significance from zero change.

rate of at least $130 / \mathrm{min}$ was obtained. At this point the infusion was discontinued and serial electrocardiograms were taken immediately, 5 minutes, and ro minutes after the infusion was discontinued. Though 12 leads were taken, the ST-T changes were measured only in 4 (I, aVF, V2, V6) for statistical evaluation with standard statis-

TABLE 2 Mean differences in the response of $S T$ changes and $T$ changes to isoprenaline between normal controls and patients with coronary heart disease, and statistical significance

\begin{tabular}{lllll}
\hline Lead & $\Delta S T$ & $t$ & $\Delta T$ & $t$ \\
\hline I & $-\mathrm{I} \cdot 7 \mathrm{I}$ & $9.98^{\star}$ & -0.17 & 0.30 \\
aVF & $-0.8 \mathrm{I}$ & $\mathrm{1} \cdot 50$ & $-0.2 \mathrm{I}$ & 0.18 \\
V2 & $-2.2 \mathrm{I}$ & $4.69^{\star}$ & -0.43 & 0.53 \\
V6 & $-\mathrm{I} \cdot 60$ & $5.28^{\star}$ & $-0.5 \mathrm{I}$ & 1.04 \\
\hline
\end{tabular}

$\star=P=0.01$. tical methods ( $\chi^{2} ; \mathrm{t}$ test). $\mathrm{Q}, \mathrm{R}, \mathrm{S}$, and T deflections were measured according to criteria of the American Heart Association (1954).

\section{Results}

Table I shows the mean changes of the ST segment and of the $T$ wave (differences before and after isoprenaline), with standard deviation (SD), and statistical significance (t test) in the normal control groups and in the group of patients with coronary heart disease. A small, but statistically significant ST depression occurred in the normal control group only in aVF and V6, while in the patients with ST depression it was much more pronounced and highly significant in all leads. The mean changes of the $T$ wave do not show striking differences between the two groups, because the direction of $\mathrm{T}$ wave changes was not uniform.

TABLE 3 Distribution in four leads of significant ST changes ( $>\mathrm{I} \mathrm{mm}$ ) and $T$ wave changes $(>2 \mathrm{~mm}$ ) after isoprenaline injection in normal controls and in patients with coronary heart disease

\begin{tabular}{llcclllll}
\hline & $>I \mathrm{~mm}$ & $<\mathrm{Imm}$ & Total & $\chi^{2}$ & $>2 \mathrm{~mm}$ & $<2 \mathrm{~mm}$ & Total & $\chi^{2}$ \\
\hline Normal & 10 & 46 & 56 & & 10 & 46 & 56 & \\
Patients & 67 & I & 68 & 84.91 & 42 & 23 & 65 & 26.83 \\
Total & 77 & 47 & 124 & P =0.0001 & 52 & 69 & I2I & P=0.00I
\end{tabular}

TABLE 4 Incidence of changes of $T$ wave after isoprenaline in direction of negativity (lowering, inversion) or positivity (higher, less inverted, reversal of inversion) dependent on initial $T$ wave (positive; flat or negative). All four leads are pooled. Significance $(P)$, calculated with $\chi^{2}$ test

\begin{tabular}{|c|c|c|c|c|c|c|c|c|c|c|c|c|c|c|}
\hline Group & - & + & Total & $P$ & Group & - & + & Total & $P$ & Group & - & + & Total & $P$ \\
\hline I & $\begin{array}{r}I \\
25\end{array}$ & $\begin{array}{r}30 \\
2\end{array}$ & $\left.\begin{array}{l}31 \\
27\end{array}\right\}$ & $<0.0001$ & $\begin{array}{l}\text { I } \\
\text { II }\end{array}$ & $\begin{array}{l}I \\
7\end{array}$ & $\begin{array}{l}30 \\
18\end{array}$ & $\left.\begin{array}{l}31 \\
25\end{array}\right\}$ & $<0.01$ & $\begin{array}{l}\text { I } \\
\text { II }\end{array}$ & $\begin{array}{r}25 \\
7\end{array}$ & $\begin{array}{r}2 \\
18\end{array}$ & $\left.\begin{array}{l}27 \\
25\end{array}\right\}$ & $<0.0001$ \\
\hline Cotal & 26 & 32 & 58 & & Total & 8 & 48 & 56 & & Total & 32 & 20 & 52 & \\
\hline
\end{tabular}

Group I-Normal controls; initial T positive.

Group II-Coronary art. patients, initial T positive.

Group III-Coronary art. patients, initial $T$ flat or negative. 
The difference in the reaction of the ST segment between the normal control group and the group of patients was highly significant except in aVF, while the differences of $T$ wave changes were not significant (Table 2 ).

In view of the differences in the direction of ST-T changes in different patients, we analysed the incidence of changes in either direction of the ST segment exceeding I mm, and of the $T$ wave exceeding $2 \mathrm{~mm}$ in the pooled material of all four leads (Table 3 ). The justification for this procedure is the experience with the exercise test; reversal of an initially inverted $\mathrm{T}$ wave has been considered since Master (1935) as an abnormal response. The incidence of ST changes $>\mathrm{I} \cdot 0 \mathrm{~mm}$ and $\mathrm{T}$ changes over $2 \mathrm{~mm}$ was much greater in the patients, and this difference, analysed by means of the $\chi^{2}$ test, was highly significant.

The $T$ wave changes were further analysed in regard to the initial (preinjection) direcLtion; positive, flat, or inverted. Flat and inverted initial $T$ waves were combined, since both are abnormal in the leads investigated. The incidence of changes in the direction of negativity or positivity was analysed in three subgroups: I-normal controls; II-patients with coronary artery disease and positive $T$ - waves; III-patients with initially inverted or flat $T$ waves. Since the incidence of no (or minor) changes was included in the analysis of Table 3, Table 4 refers only to significant
T wave changes in either direction. All group comparisons show highly significant differences $\left(\chi^{2}\right)$. Nearly all changes in group I are in the direction of greater positivity, and in group II in the direction of greater negativity. In contrast to group II, the changes of group III in the direction of positivity (i.e. reversal of $T$ inversion) are about $2 \frac{1}{2}$ times more frequent than greater inversion, but less frequent than in the normal control. For this reason, group III could obviously not be subjected to the type of statistical analysis employed in Table 4. The typical change in the electrocardiogram after isoprenaline injection in a patient with initial $\mathrm{T}$ inversion is, therefore, greater ST depression associated with reversal of the $T$ wave. This pattern, typical for subendocardial ischaemia, occurs in spontaneous coronary insufficiency and occasionally after exercise, though sloping down ST depression is more frequent.

Fig. I illustrates the typically normal response to isoprenaline with an increase in the $T$ voltage in some of the leads but without any significant ST change. Fig. 2 and 3 depict the typical ST-T changes noted in an abnormal isoprenaline response. A $\mathrm{T}$ wave reversal is noted in lead I of Fig. 3 after infusion of isoprenaline. It is of interest to note that 5 minutes later the $T$ wave has reverted to the negative $T$ wave seen in the baseline tracing.

There was no essential difference in the response to isoprenaline in the younger and

FIG. I Normal response to isoprenaline.

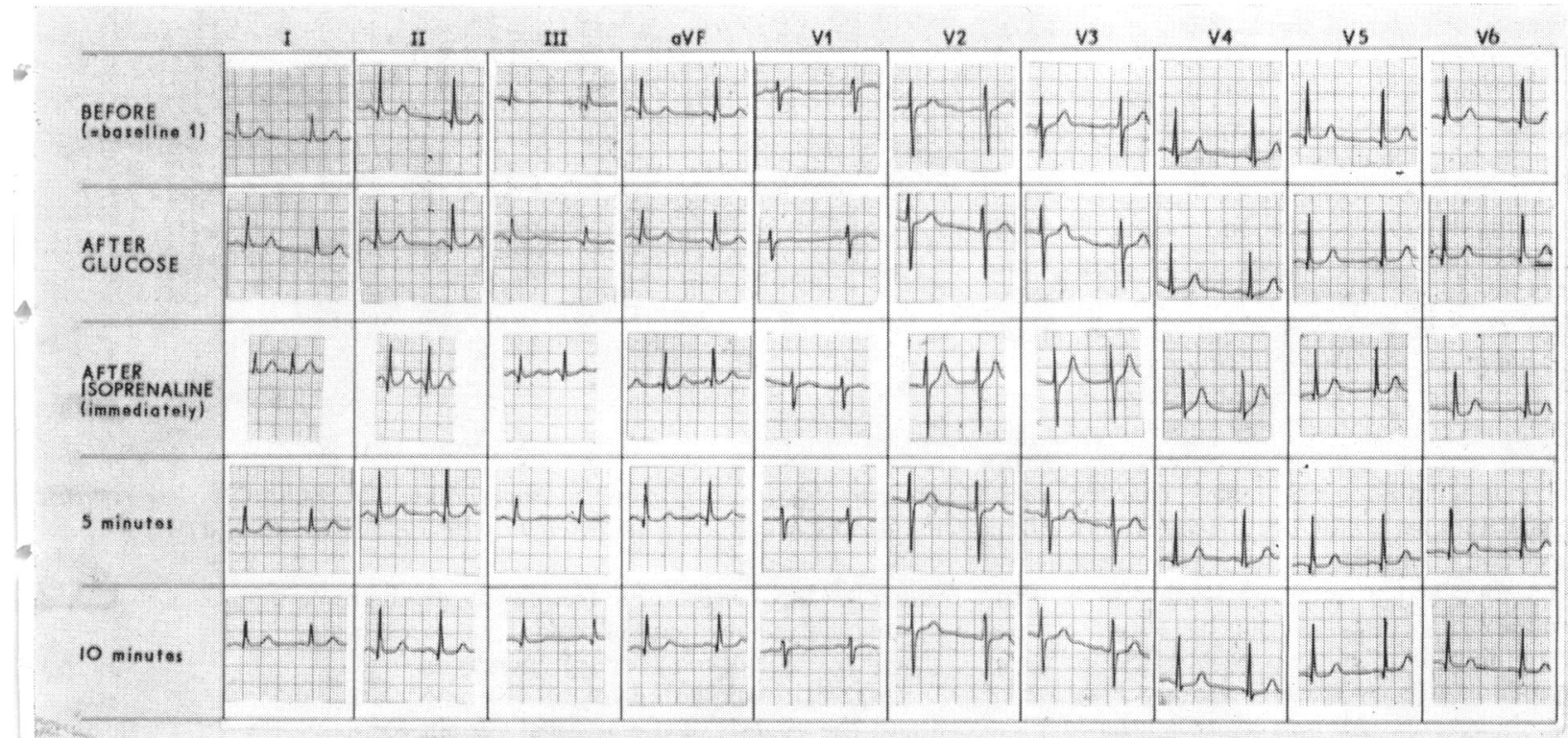


older normal control groups; therefore, the analysis was limited to the age-matched control group. As anticipated, the incidence of abnormal responses in the group of patients with suspected coronary disease was somewhat in between that of the normal control group and that of patients with documented coronary artery disease.

\section{Discussion}

In ro controls not included in the statistical analysis of the isoprenaline study an electrocardiogram was taken after the infusion of ro $\mathrm{g}$ glucose as 5 per cent glucose in water over a 30-minute period, and in no instance was a change seen in a subsequent cardiogram. Less than I $\mathrm{g}$ glucose was infused in each of our test subjects. None of the subjects in either the normal or abnormal groups showed any change in the electrocardiographic response to infusing 5 per cent glucose and water. In 4 coronary disease patients vectorcardiograms were taken before and after intravenous infusion of isoprenaline and in no case could a change in the QRS be demonstrated.

Catecholamines increase the myocardial oxygen consumption and thus produce a stress situation similar to the effect of exercise (Ferrans et al., 1964; Raab et al., 1962; Raab, 1962). Holmberg showed that an increase in the heart rate is the chief reason for the greater oxygen consumption and coronary blood flow in exercise (1967). It has also been shown that catecholamines create an excessive and wasteful consumption of oxygen by the myocardium independent of the presence or absence of external work (Raab et al., 1962). In patients with impairment of coronary circulation, the increased oxygen demand cannot be met, resulting in myocardial hypoxaemia (Raab et al., 1962).

The clinical corollary is angina produced by physiological stimulation of catecholamines through excitement, smoking, and cold exposure (Raab, 1962). In 1930, Levine, Ernstene, and Jacobson noted that epinephrine given for the relief of an asthma attack in a coronary disease patient regularly produced severe angina. They subsequently proposed this as a diagnostic test for angina pectoris. Pathological outpouring of catecholamines in cases of phaeochromocytoma frequently causes angina and subsequently even myocardial necrosis (Raab, 1962). Propranolol, a beta-adrenergic blocking agent, is often helpful in decreasing the frequency of angina attacks by counteracting the action of catecholamines. Moreover, drugs that deplete the body stores of catecholamines such as

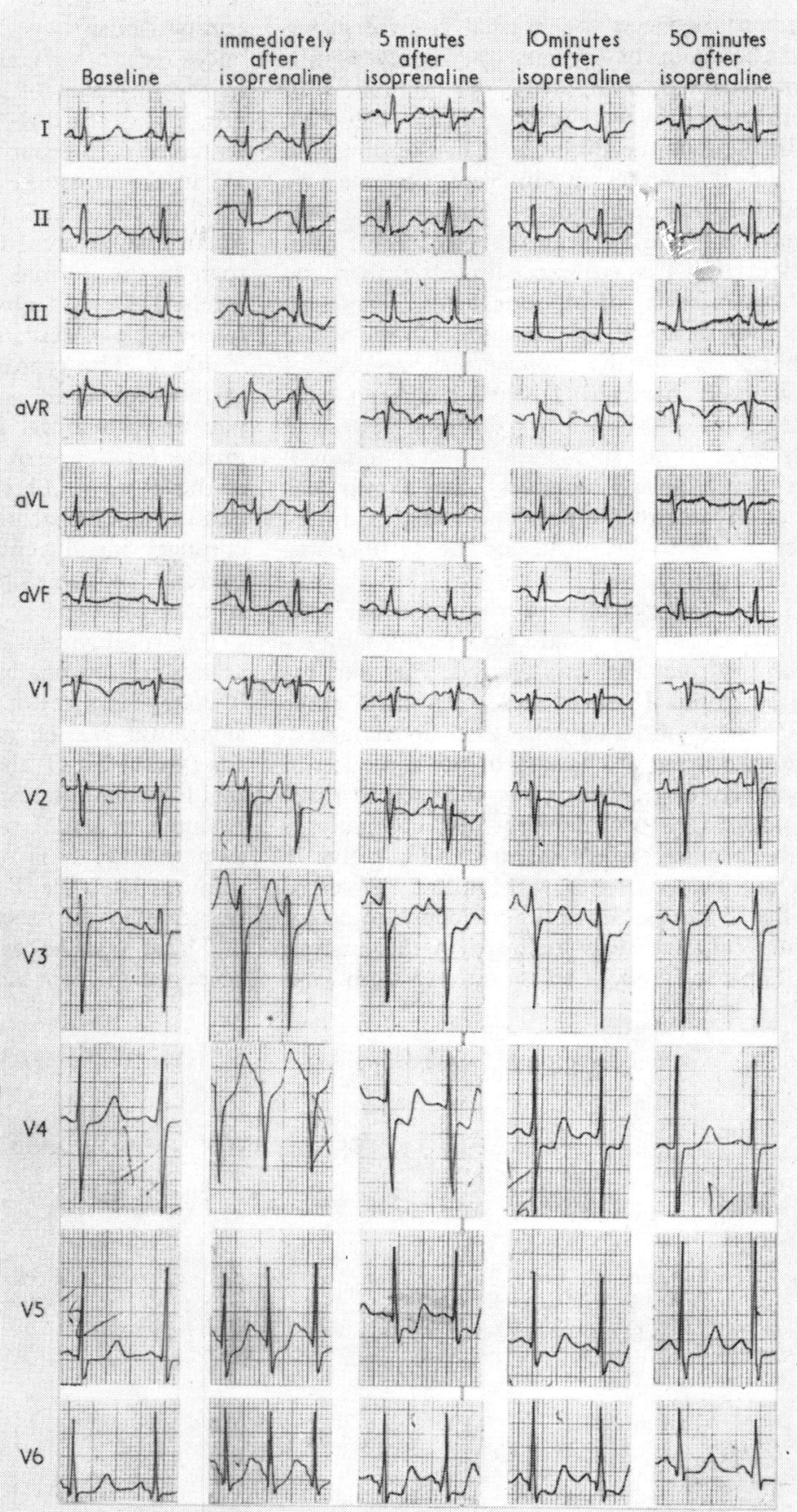

FIG. 2 Ischaemic response to isoprenaline with relatively slow return to baseline in a patient with initial positive $T$ wave in $I, a V F, V 6$.

rauwolfia or guanethidine frequently produce dramatic improvement of angina in cases of phaeochromocytoma or hyperthyroidism. With this in mind one might also speculate about the genesis of the atypical variant form of angina characterized by frequent, almost 


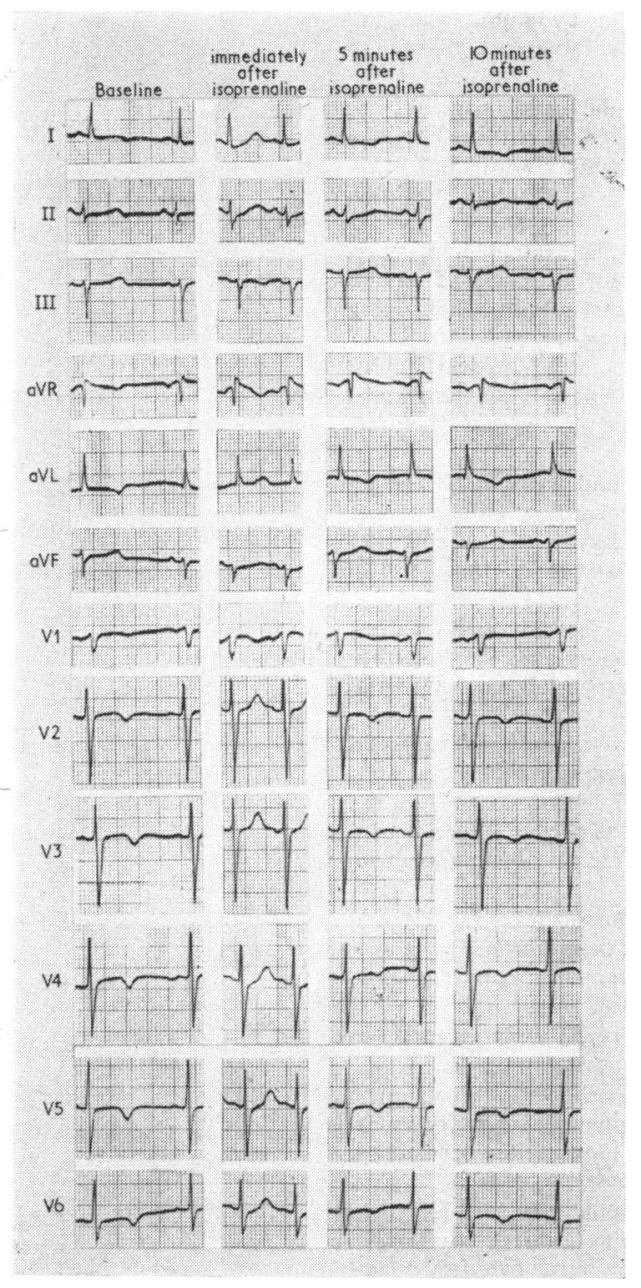

FIG. 3 Ischaemic response to isoprenaline in - a patient with initial diphasic or negative $T$ wave in $I, V 2$, and V6.

rhythmic, episodes of chest pain seemingly unrelated to physical exertion. Many of these subjects have a normal electrocardiographic response to exercise yet show dramatic ST-T changes during an attack, not unlike those $r$ individuals with phaeochromocytoma. It is therefore difficult to escape the possibility of catecholamines playing a prominent role in the production of this type of angina.

Currently the exercise tolerance test is the most frequently employed stress test for the farly recognition of coronary artery disease (Master and Rosenfeld, 196I); however, the test does carry a small risk of precipitating severe coronary insufficiency. Furthermore, the performance and interpretation of the exercise tolerance test has been and continues to be the subject of much discussion and controversy (Mattingly, 1962; Sheffield and
Reeves, 1965). Both false negative and false positive responses to exercise are frequent. It is of interest that three of our coronary disease patients with an abnormal response to isoprenaline had normal responses to a double Master's test; however, a progressive exercise test was not performed. The exercise test also requires that the test subject not only be ambulatory but also quite active physically in order to get a valid test. In the isoprenaline test the subject lies quietly in bed.

'Atrial pacing', i.e. increasing the heart rate by electrical stimulation with an electrode in the right atrium, is an excellent test to produce myocardial ischaemia (Linhart et al., 1969; Lau et al., 1968). The physiological basis for this test is the high correlation between heart rate and myocardial oxygen consumption (Holmberg, 1967). Therefore, when an individual with coronary atherosclerosis reaches a critical heart rate, ischaemic ST-T changes will develop. Unfortunately, the need for cardiac catheterization limits the potential application of this procedure.

The isoprenaline test itself is simple to perform. The entire procedure generally did not take longer than 20 minutes. In most instances the study was done on outpatients. The amount of isoprenaline infused is significantly less than the 5 to $6 \mu \mathrm{g}$ infused intravenously per minute for therapeutic purposes. As a result of the minimal dose used, side effects, such as apprehension, tremor, headache, facial flushing, extrasystoles, and sweating, presented little or no problem in our study. The vast majority of the patients noted only an increase in heart rate and in no instance did a paroxysmal arrhythmia develop. Of greater importance is the fact that even though the patients in the coronary artery disease group had abnormal electrocardiographic responses, none of the patients had any chest pain or dyspnoea during or after the isoprenaline infusion. This is in contrast to the experience with the exercise and hypoxaemia test. It must be emphasized that normal subjects respond to the drug simply by developing a sinus tachycardia, but abnormal subjects have a typically ischaemic ST-T response. In one instance only (Fig. 2) the electrocardiogram did not return to the preinfusion baseline ro minutes after discontinuing isoprenaline. In all cases, once the cardiogram returned to the baseline level it did not subsequently change. Therefore, it is reasonable to assume that one may discontinue the test after the electrocardiogram has returned to the baseline level. Hypoxaemia and drug tests (pitressin, adrenaline, ergonovine) have been suggested as diagnostic tests (Levy, Bruenn, and Russell, 
1939), but have not gained wide clinical use probably because of side effects, slow reversibility, and possible medical-legal implications. The absence of side effects and prompt reversibility in our admittedly small series, together with the wide therapeutic use in much higher dosage, is encouraging for continuing the study of isoprenaline as a tool in the early diagnosis of ischaemic heart disease.

\section{References}

Ahn, C., and Vasko, J. S. (I969). Influences of coronary blood flow and hypoxia upon the cardiac responses to isoproterenol. Annals of Thoracic Surgery, 7, 500 .

American Heart Association, Committee on Electrocardiography (1954). Report: Recommendations for standardization of electrocardiographic and vectorcardiographic leads. Circulation, 10, 564.

Bellet, S. (1963). Clinical Disorders of the Heart Beat, and ed. Lea and Febiger, Philadelphia.

Bluestone, R., and Harris, A. (1965). Treatment of heart-block with long-acting isoprenaline. Lancet, I, 1299.

Cohen, L. S., Elliott, W. C., Klein, M. D., and Gorlin, R. (1966). Coronary heart disease. Clinical, cinearteriographic and metabolic correlations. American fournal of Cardiology, 17, I 53.

Dodge, H. T., Lord, J. D., and Sandler, H. (1960). Cardiovascular effects of isoproterenol in normal subjects and subjects with congestive heart failure. American Heart fournal, 60, 94.

Dodge, H. T., and Murdaugh, H., Jr. (1957). Cardiovascular-renal effects of isoproterenol in congestive heart failure. Circulation, 16, 873

Eckstein, J. W., and Hamilton, W. K. (1957). Effects of sympathomimetic amines on forearm venous distensibility, pressure and volume. Circulation, 16, 875.

Ferrans, V. J., Hibbs, R. G., Black, W. C., and Weilbaecher, D. G. (1964). Isoproterenol-induced myocardial necrosis. A histochemical and electron microscopic study. American Heart fournal, 68, 71.

Holmberg, S. (1967). Effect of severe muscular work on total and coronary circulation in man in relation to findings in the coronary arteriogram. In Coronary Circulation and Energetics of the Myocardium. Ed. by G. Marchetti and B. Taccardia. Karger, New York.
Krasnow, N., Rolett, E. L., Yurchak, P. M., Hood, W. B., Jr., and Gorlin, R. (1964). Isoproterenol and cardiovascular performance. American fournal of Medicine, 37, 514.

Lafontant, R. R., Feinberg, H., and Katz, L. N. (I962). Partition of coronary flow and cardiac oxygen extraction between coronary sinus and other coronary drainage channels. Circulation Research, II, 686.

Lau, S. H., Cohen, S. I., Stein, E., Haft, J. I., Kinney, M. J., Young, M. W., Helfant, R. H., and Damato, A. N. (1968). Controlled heart rate by atrial pacing in angina pectoris. Circulation, 38, 711 .

Levine, S. A., Ernstene, A. C., and Jacobson, B. M. (1930). The use of epinephrine as a diagnostic test for angina pectoris. Archives of Internal Medicine, 45, 191 .

Levy, R. L., Bruenn, H. G., and Russell, N. G., Jr. (1939). The use of electrocardiographic changes caused by induced anoxemia as a test for coronary insufficiency. American fournal of the Medical Sciences, 197, 241.

Linhart, J. W., Hildner, F. J., Barold, S. S., Lister, J. W., and Samet, P. (I969). Left heart hemodynamics during angina pectoris induced by atrial pacing. Circulation, 40, 483.

Master, A. M. (1935). The two-step test of myocardial function. American Heart fournal, ro, 495.

Master, A. M., and Rosenfeld, I. (I96I). Criteria for the clinical application of the 'two-step' exercise test. fournal of the American Medical Association, 178, 283.

Mattingly, T. W. (1962). The postexercise electrocardiogram. Its value in the diagnosis and prognosis of coronary arterial disease. American fournal of Cardiology, 9, 395.

Mendez, R., and Kabela, E. (1966). Beta-recepters in coronary vessels. Lancet, $1,907$.

Raab, W. (1962). The sympathogenic biochemical trigger mechanism of angina pectoris. Its therapeutic suppression and long-range prevention. American fournal of Cardiology, 9, 576.

Raab, W., Van Lith, P., Lepeschkin, E., and Herrlich, H. C. (1962). Catecholamine-induced myocardial hypoxia in the presence of impaired coronary dilatability independent of external cardiac work. American fournal of Cardiology, 9, 455.

Sheffield, L. T., and Reeves, T. J. (1965). Graded exercise in the diagnosis of angina pectoris. Modern Concepts of Cardiovascular Disease, 34, I. 